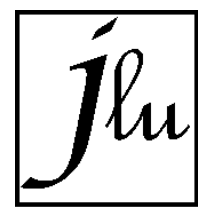

https://jurnal.univpgripalembang.ac.id/index.php/luminous

\title{
PENGEMBANGAN MEDIA PEMBELAJARAN PHYSICS ANIMATION (PHYTION) PADA MATERI FISIKA KUANTUM
}

\author{
Mohamad Ibnu ${ }^{1 *}$, Andri Suherman ${ }^{2}$, Asep Saefullah ${ }^{3}$ \\ ${ }^{123}$ Program Studi Pendidikan Fisika, Fakultas Keguruan dan Ilmu Pendidikan, Universitas Sultan Ageng Tirtayasa, \\ Kota Serang, Indonesia \\ Email Penulis : muhammadibnu120@gmail.com
}

Received: 28 April 2020. Accepted: 25 Juni 2020. Published: Juli 2020

\begin{abstract}
Abstrak
Penelitian ini bertujuan untuk mengembangkan dan mengetahui kelayakan media physics animation (phytion) pada materi fisika kuantum. Metode penelitian yang digunakan pada penelitian ini adalah metode penelitian dan pengembangan (Reserch and Development) dengan model 4-D yaitu define, design, development dan disseminate. Hasil penelitian untuk mengetahui kelayakan physics animation dilakukan uji validasi oleh ahli materi dan ahli media serta uji coba terbatas pada peserta didik kelas XII. Hasil validasi pada media physics animation (phytion) oleh ahli materi sebesar $97,2 \%$ yang dikategorikan sangat layak. dan ahli media sebesar $98.9 \%$ yang dikategorikan sangat layak. Serta mendapat respon dari peserta didik dengan kategori sangat layak sebesar 95,1\%. Berdasarkan hasil penelitian bahwa media physics animation layak digunakan sebagai media pembelajaran fisika.
\end{abstract}

(C) 20XX Pendidikan Fisika FKIP UPGRI Palembang

Kata Kunci: Penelitian dan pengembangan, physics animation, video animasi, fisika kuantum

\section{PENDAHULUAN}

Dunia pendidikan saat ini semakin berkembang, berbagai macam pembaharuan yang dilakukan agar dapat meningkatkan kualitas pendidikan, maka diperlukan berbagai terobosan baik dalam pengembangan kurikulum, inovasi pembelajaran, dan pemenuhan sarana serta prasarana pendidikan. Untuk meningkatkan proses pembelajaran, maka guru dituntut untuk membuat pembelajaran menjadi lebih inovatif yang mendorong siswa dapat belajar secara 
optimal baik di dalam belajar mandiri maupun didalam pembelajaran di kelas.

Pendidikan pada zaman ini dituntut agar dapat mengikuti perkembangan teknologi yang kini sedang berkembang pesat. Keahlian dalam bidang teknologi kini juga dimanfaatkan untuk mengembangkan ilmu pengetahuan. Salah satu manfaat serta tujuan pembelajaran adalah untuk memudahkan guru menentukan kegiatan belajar dan media pengukuran.

Mutu pendidikan yang baik dapat terwujud dengan menerapkan pembelajaran secara efektif yang prosesnya berjalan dengan lancar serta sesuai dengan tujuan pembelajaran. Terdapat beberapa faktor yang mempengaruhi proses pembelajaran seperti pendidik, fasilitas, metode, serta media yang digunakan selama proses pembelajaran.

Media pembelajaran merupakan seperangkat alat bantu atau perlengkapan yang digunakan oleh guru atau pendidik dalam rangka berkomunikasi dengan siswa (Sudarwan, 1994).

Terdapat beberapa jenis media pembelajaran yang dapat digunakan dalam proses pembelajaran, namun pada penelitian ini media yang digunakan berupa media audio-visual yaitu media yang mengkobinasikan materi auditif yang merangsang pendengaran dan materi visual yang merangsang penglihatan yaitu media video animasi.

Berdasarkan hasil Observasi di MAN 2 Kota Serang, media bantu yang digunakan oleh guru selama pembelajaran hanya berbatas pada text book atau powerpoint dan belum mampu menarik perhatian siswa, menyebabkan penyampaian materi ajar menjadi kurang bervariasi sehingga belum tercapainya tujuan pembelajaran yang diinginkan, fakta lain berdasarkan hasil wawancara dengan guru fisika di MAN 2 Kota Serang, kesulitan dalam menyampaikan materi fisika yang abstrak salah satunya pada fisika kuantum dan keterbatasan waktu dalam membahas materi ini karena berada pada semester genap dimana waktu tersebut digunakan untuk persiapan Ujian Nasional (UN). Maka hal ini dapat diatasi dengan media.

Berdasarkan penelitian sebelumnya Fisika kuantum adalah materi fisika yang membahas tentang sebuah fenomena seperti 
radiasi benda hitam, efek fotolistrik dan efek compton. Materi fisika kuantum adalah materi yang lebih abstrak dibandingkan materi yang lain. Selain itu konsep-konsep dalam fisika kuantum juga termasuk konsep yang abstrak sehingga perlu divisualisasikan (Gunawan, 2013).

Video Animasi diharapkan dapat membantu guru untuk menyampaikan materi dengan waktu yang efektif dan pembelajaran lebih menyenangkan dan tidak membosankan. Dari penelitian yang dilakukan oleh Nurokhimah, dkk (2012) pemanfaatan media animasi fisika sebagai media pembelajaran dapat meningkatkan motivasi belajar sebesar 19,39\%. Dengan demikian, tujuan pembelajaran fisika akan tercapai secara optimal.

\section{METODE}

Metode yang digunakan dalam penelitian ini adalah metode penelitian dan pengembangan (Research and Development) yaitu metode yang mengahsilkan produk tertentu. Adapun tahapan penelitian dan pengembangan media ini menggunakan jenis penelitian pengembangan 4-D. Menurut Thiagarajan (1945:5) terdapat empat tahapan yang meliputi pendefinisian (define), desain (design), pengembangan (develop), dan penyebaran (disseminate).

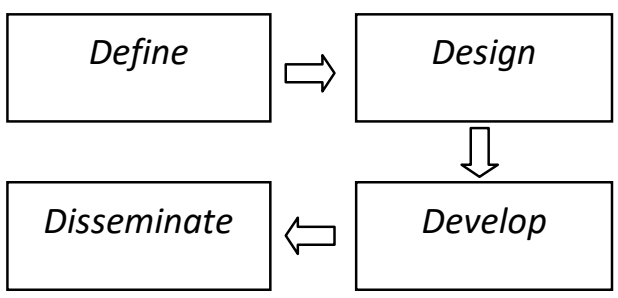

Gambar 1. Tahapan 4-D

Data yang dikumpulkan berasal dari ahli media, ahli materi dan'respon siswa. Adapun sampel pada penelitian ini adalah dua orang dosen fisika dan dua orang guru fisika serta 15 peserta didik MAN 2 Kota Serang.

Instumen yang digunakan dalam penelitian ini adalah lembar penilaian kelayakan media dengan skala Guttman

Tabel 1. Kriteria Penilaian Kelayakan

\begin{tabular}{c|c|c}
\hline No & Skor & Ket \\
\hline 1 & 1 & Ya \\
2 & 0 & Tidak \\
\hline
\end{tabular}


Data dari validator dan respon siswa kemudian dihitung dengan rumus statistik persentase dengan rumus

$$
N P=\frac{R}{S M} \times 100 \%
$$

Keterangan: "NP" adalah nilai persentase, "R" adalah skor mentah yang diperoleh, "SM" adalah skor maksimum ideal.

Nilai persentasae yang telah dihitung kemudian diubah ke dalam nilai kualitatif dengan kriteria pada tabel 2 .

Tabel 2. Kategori kelayakan media

\begin{tabular}{c|c}
\hline Skala Kelayakan & Kategori \\
\hline $81-100 \%$ & Sangat Layak \\
$61-80 \%$ & Layak \\
$41-60 \%$ & Cukup Layak \\
$21-40 \%$ & Kurang Layak \\
$0-20 \%$ & Sangat Kurang Layak \\
\hline
\end{tabular}

\section{HASIL DAN PEMBAHASAN}

Tahap pertama define (pendefinisian) yaitu menganalisis kebutuhan di sekolah tersebut serta menentukan kurikulum yang digunakan di MAN 2 Kota Serang, tahap kedua yaitu design (perancangan) adalah dengan merancang flowchart, script dan storyboard, tahap ketiga develop (pengembangan) pada tahap ini bertujuan untuk menghasilkan produk pengembangan berupa video physics animasi, terdapat delapan video yang dihasilkan pada penelitian ini. Setelah jadi produk akhir yang telah divalidasi serta direvisi kemudian di uji terbatas selanjutnya tahap disseminate (penyebaran), pada tahap ini hanya dilakukan penyebaran terbatas yaitu menyebarluaskan media ke sekolah.

\section{Gambar 2. Tampilan Media}
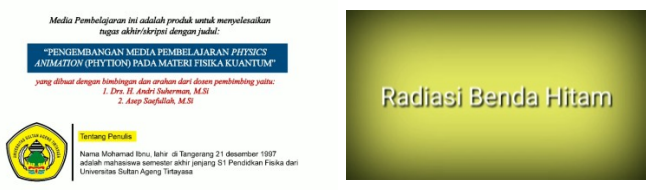

a) Tampilan profil

b) Tampilan judul materi

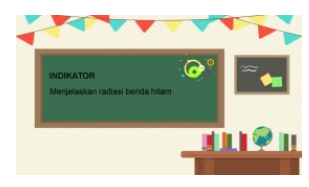

c) Tampilan indikator

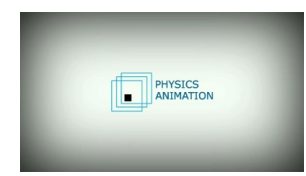

d) Tampilan logo physics animation

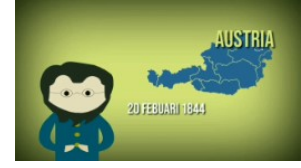

e) Isi Materi f) Soal

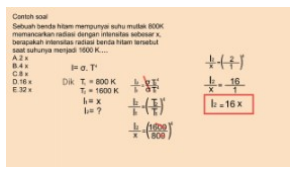

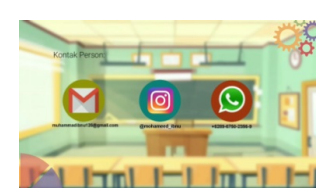

g) Penutup
Setelah media sudah dibuat kemudian divalidasi uji kelayakan oleh ahli media dan ahli 


\begin{tabular}{|c|c|c|c|c|c|c|c|c|}
\hline \multirow[t]{2}{*}{ No } & \multirow{2}{*}{$\begin{array}{c}\text { Aspek } \\
\text { Penilaian }\end{array}$} & \multicolumn{3}{|c|}{ Ahli ke- } & \multirow{2}{*}{$\begin{array}{c}\text { Jumlah } \\
\text { skor }\end{array}$} & \multirow[t]{2}{*}{ Skor ideal } & \multirow{2}{*}{$\begin{array}{c}\text { Persentase } \\
(\%)\end{array}$} & \multirow[t]{2}{*}{ Kategori } \\
\hline & & 1 & 2 & 3 & & & & \\
\hline 1 & Tampilan & 11 & 11 & 10 & 32 & 33 & $96,9 \%$ & Sangat layak \\
\hline 2 & Tata Laksana & 2 & 2 & 2 & 6 & 6 & $100 \%$ & Sangat layak \\
\hline 3 & Kaidah & 3 & 3 & 3 & 9 & 9 & $100 \%$ & Sangat layak \\
\hline \multicolumn{5}{|c|}{ Rata-rata skor keseluruhan } & & & $98,9 \%$ & Sangat layak \\
\hline
\end{tabular}

sesuai saran dan pendapat para ahli, setelah

selesai direvisi kemudian uji terbatas oleh 15

Tabel 4. Hasil Validasi Ahli Media

peserta didik kelas XII MAN 2 Kota Serang.

\section{Hasil Kelayakan Media Oleh Ahli Media}

Validasi oleh ahli media dilakukan untuk menilai kelayakan media physics animation dari segi desain media. Secara keseluruhan hasil kelayakan oleh ahli media memperoleh tingkat persentase sebesar $98,9 \%$ dengan kategori sangat layak. Selain hasil validasi oleh ahli media sangat layak, perbaikan terhadap media tetap dilakukan sesuai saran dari ahli media. Adapaun perbaikan yang dilakukan pada media diantaranya, pemilihan warna kurang kontras, suara narrator sedikit kecil,

\section{Hasil Kelayakan Media Oleh Ahli Materi}

Data hasil kelayakan oleh ahli materi disajikan pada tabel 5 serta suara musik yang terlalu besar. Adapun persentase kelayakan media oleh ahli media tiap aspeknya disajikan dalam gambar 3 .

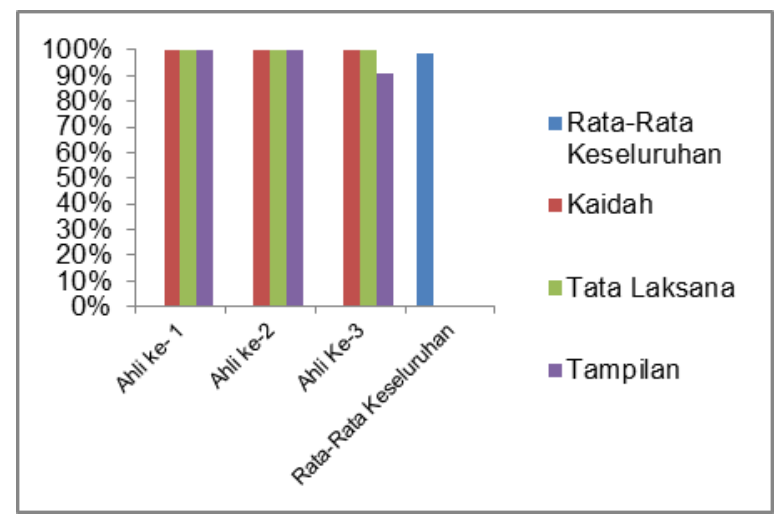

Gambar 3. Grafik Validasi Ahli Media 
Tabel 5. Hasil Valdiasi Ahli Materi

\begin{tabular}{|c|c|c|c|c|c|c|c|c|}
\hline \multirow[t]{2}{*}{ No } & \multirow{2}{*}{$\begin{array}{c}\text { Aspek } \\
\text { Penilaian }\end{array}$} & \multicolumn{3}{|c|}{ Ahli ke- } & \multirow{2}{*}{$\begin{array}{c}\text { Jumlah } \\
\text { skor }\end{array}$} & \multirow[t]{2}{*}{ Skor ideal } & \multirow{2}{*}{$\begin{array}{c}\text { Persentase } \\
(\%)\end{array}$} & \multirow[t]{2}{*}{ Kategori } \\
\hline & & 1 & 2 & 3 & & & & \\
\hline 1 & Pembelajaran & 5 & 6 & 6 & 17 & 18 & $94,4 \%$ & Sangat layak \\
\hline 2 & Isi Materi & 8 & 8 & 8 & 17 & 24 & $100 \%$ & Sangat layak \\
\hline \multicolumn{6}{|c|}{ Rata-rata skor keseluruhan } & & $97,2 \%$ & Sangat layak \\
\hline
\end{tabular}

Validasi oleh ahli materi dilakukan untuk menilai kelayakan media physics animation dari segi materi. Secara keseluruhan hasil kelayakan oleh ahli media memperoleh tingkat persentase sebesar $97,2 \%$ dengan kategori sangat layak. Adapun persentase kelayakan media ahli materi tiap aspek disajikan pada gambar 4 .

\section{Respon Peserta Didik}

Data yang diperoleh dari peserta didik disajikan pada tabel 6 .

Tabel 6. Respon Siswa

\begin{tabular}{llcccc} 
No & $\begin{array}{c}\text { Aspek Respon } \\
\text { Peserta didik }\end{array}$ & $\begin{array}{c}\text { Jumlah skor } \\
\text { Responden }\end{array}$ & Skor Ideal & Persentase & Kategori \\
\hline 1 & Materi & 57 & 60 & $95 \%$ & Sangat layak \\
2 & Kebahasaan & 28 & 30 & $93 \%$ & Sangat layak \\
3 & Penyajian & 34 & 35 & $97 \%$ & Sangat layak \\
\hline Rata-rata skor keseluruhan & & & $95,1 \%$ & Sangat layak \\
\hline
\end{tabular}

Uji coba terbatas dilakukan oleh 15 peserta didik bertujuan untuk mengetahui respon siswa mengenai media pembelajaran. Selain dalam bentuk tabel disajikan juga dalam bentuk grafik pada gambar 5.

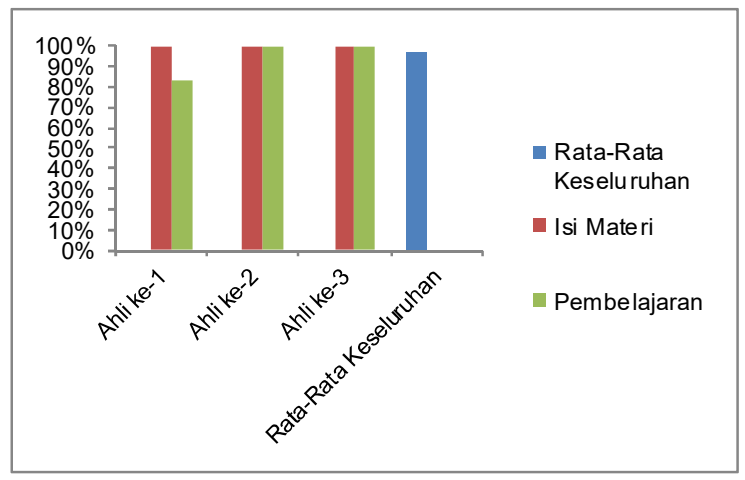

Gambar 4. Grafik Validasi Materi 


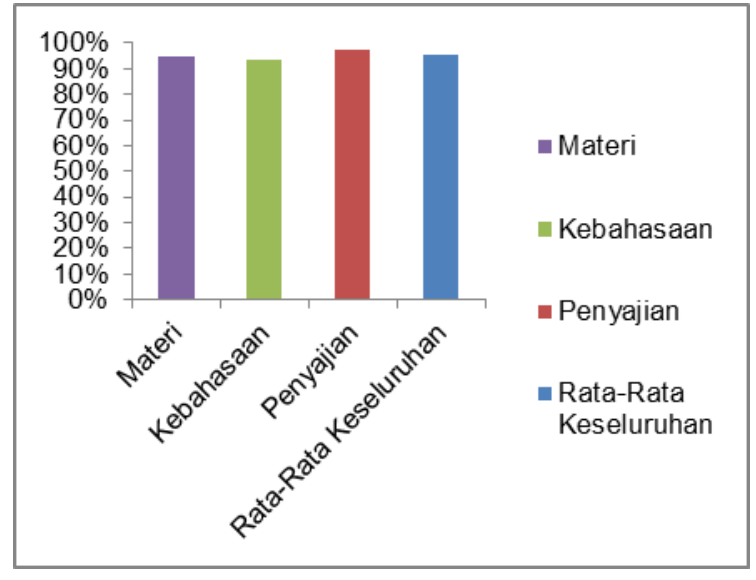

Gambar 5. Grafik Validasi Respon Siswa

\section{KESIMPULAN DAN SARAN}

\section{Kesimpulan}

Media pembelajaran Physics animation pada materi fisika kuantum telah dilakukan uji validasi ahli media dan dinyatakan sangat layak untuk digunakan dalam pembelajaran fisika dengan hasil validasi sebesar $98,9 \%$ dengan kategori sangat layak. Pada uji validasi ahli materi dinyatakan sangat layak untuk digunakan dalam pembelajaran fisika dengan hasil validasi sebesar $97,2 \%$ dengan kategori sangat layak, serta hasil respon peserta didik terhadap media physics animation sebesar 95,1\% dengan kategori sangat layak digunakan untuk pembelajaran.

\section{Saran}

Media Physics animation masih terdapat kekurangan, seperti suara narrator yang kurang semangat dan beberapa animasi yang masih kaku. Maka disarankan untuk pengembangan selanjutnya diharapkan dapat memperbaiki kekurangan-kekurangan yang terdapat pada media pembelajaran physics animation.

\section{DAFTAR PUSTAKA}

Arikunto, Suharsimi. 2002. Prosedur Penelitian Suatu Pendekatan Paraktek. Jakarta: Rineka Cipta 
Arsyad,A. 2004. Media Pembelajaran. Jakarta: Raja Grafindo Persada

Aswara, Sandi, Skripsi, "Pengembangan Media Pembelajaran Fisika Berbasis Video Untuk Meningkatkan Minat dan Pemahaman Konsep Siswa SMA". Yogyakarta: Universitas Negeri Yogyakarta, 2018

Abdul Majid. Perencanaan Pembelajaran Mengembangkan Standar Kompetensi Guru (Bandung: PT.Remaja Rosdakarya,2007), hlm.181

Cheppy Riyana.2007. Pedoman Pengembangan Media Video. Jakarta: P3AI UPI

Ika Rahma Julianingrum, Binti Muchsini dan wahyu Adi, "Model Pembelajaran Artikulasi dengan Media Animasi Powtoon untuk Meningkatakan Prestasi Belajar Mata Pelajaran Akuntasi Keuangan, “Jurnal Pendidikan Akuntasi Vol.2 Nomor 2, (2016), h. 2

Kanginan, M. 2018. Fisika untuk SMA/MA Kelas XII. Jakarta: Erlangga
Liong, H.1982. Konsep Fisika Modern. Jakarta: Erlangga

Maryana,Okky Fajar Tri., dan Yuant Tiandho.2019. Fisika Kuantum. Bandung: Yrama Widya

Maesyarah, Ima Ayu, Skripsi."Pengembangan Media Pembelajaran Fisika Berbasis Powton Pada Materi Dinamika Untuk SMA Kelas X". Lampung: Universitas Islam Negeri Raden Intan Lampung, 2018

Prakosa, Gatot. 2010. Pengetahuan Dasar Animasi Indonesia. Jakarta: Fakutas Film dan Kesenian Jakarta

Rusman. 2013. Belajar dari Pembelajaran Berbasis Komputer. Bandung : Alfabeta

Salma. P, Diana Ariani dan Hilman Handoko,"Mozaik Teknologi Pendidikan ELearning”(Jakarta:Kencana,2013),h 15.

Shoimin, A. 2014. 68 Model Pembelajaran Inovatif. Yogyakarta: Ar-ruzz.

Sudarwan, Danim. 1994. Media Komunikasi Pendidikan. Jakarta : Bumi Aksara 
Sugiyono. 2006. Metode Penelitian Pendidikan (Pendekatan Kualitatif, Kunatitatif, dan $R \& D)$. Bandung : Alfabeta

Sugiyono. 2008. Metode Penelitian Pendidikan (Pendekatan Kualitatif, Kunatitatif, dan $R \& D)$. Bandung : Alfabeta

Tipler, A.P. 2004. Fisika untuk

Sains dan Teknik. Jakarta:

Erlangga
Wibowo. 2012. Evaluasi Pembelajaran Kelas Penggunaan Media Berbasis Komputer. Bandung: Alfabeta

Winarno.F.G. Ensiklopedi Bahasa Indonesia (Jakarta:PT Cipta Adi Pustaka, 1989), hlm. 326 